\title{
Anti-Bribery Due Diligence in M\&A Transactions: Have you Got it Covered?
}

\author{
Sharon Oded ${ }^{1 *}$, Daniel Ceulen ${ }^{2}$ \\ ${ }^{1}$ Professor of Corporate Compliance and Enforcement, Erasmus University Rotterdam, the Netherlands and a \\ Senior Associate at De Brauw Blackstone Westbroek; formerly, Visiting Fellow, University of California, \\ Berkeley School of Law \\ ${ }^{2}$ Senior Associate at De Brauw Blackstone Westbroek
}

*Corresponding Author: Sharon Oded, Professor of Corporate Compliance and Enforcement, Erasmus University Rotterdam, the Netherlands and a Senior Associate at De Brauw Blackstone Westbroek; formerly, Visiting Fellow, University of California, Berkeley School of Law

\begin{abstract}
Your company is up for another expansion. Management has identified a potential target company for a merger or acquisition and is eager to move on, and fast. What's next? Due diligence! A careful evaluation of the target company's risks is of great importance for the success of such a transaction. An appropriate and well-planned due diligence not only increases the odds of a successful transaction, but also minimizes your own company's liability, financial and reputational exposure. This article focuses on antibribery due diligence in M\&As and explains what anti-bribery due diligence is all about and how can it be implemented to reduce your organization's exposure to liability.
\end{abstract}

\section{INTRODUCTION}

On 16 June 2017 the Department of Justice ("DOJ") issued its first FCPA Pilot declination letter under the Trump administration. ${ }^{1}$ As a result of this firstborn enforcement action, Linde North America Inc. and Linde Gas North America LLC ("Linde") had to disgorge almost \$8 million relating to alleged illegal gain, and to forfeit $\$ 3.4$ million, which constituted corrupt proceeds owed to companies involved in the scheme. According to the declination agreement, between 2006 and 2009 the New Jersey company, Spectra Gases, Inc. ("Spectra"), which was acquired by Linde in October 2006, made corrupt payments to high-level officials at a state-owned entity in Georgia in connection with local asset deals. Interestingly enough, the DOJ's investigation revealed that the corrupt arrangements leading to Spectra gaining those beneficial deals, were made by Spectra prior to Linde's acquisition of Spectra. What could have Linde done better to avoid the questionable honor of commencing the current administration FCPA docket? What could other companies, parties of merger and acquisition ("M\&A") transactions do to mitigate bribery and corruption risks? Anti-bribery due diligence!

In this article, we explore what anti-bribery due diligence is all about and why and when it is required. We subsequently describe the process of conducting anti-bribery due diligence and propose practical tips on how to deal with challenges preventing an appropriate due diligence from being executed before entering into an M\&A transaction. Finally, we briefly highlight follow-up steps that should be considered once due diligence is completed.

\section{BRIBERY AND CORRUPTION RISKS IN M\&A}

Recent years have seen the tremendous enhancement of law enforcement actions against corrupt practices. Thus far, there is no indication that the rigid approach towards anti-corruption enforcement is going to change under the current Administration in Washington DC. Hence, and as we learned from Linde's declination, parties to M\&A transactions are expected to continue facing the risk of inheriting bribery and corruption-related liabilities as part of their transaction.

\footnotetext{
${ }^{1}$ U.S. DOJ Inclination letter agreement re. Linde North America Inc. and Linde Gas North America LLC of June 16, 2017, available at: https://www.justice.gov/criminal-fraud/file/974516/download.
} 


\subsection{What do Anti-Bribery Risks have to do with M\&A?}

By acquiring a target company, a purchaser acquires a set of liabilities, including those arising from pre-existing bribery and corruption violations. Accordingly, a shift of ownership in corporations does not provide the purchaser with any legal defense in relation to misconduct that occurred before the transaction was concluded. The successor owner inherits the liability arising from bribery and corruption practices even when at the time of occurrence, the purchaser was not the owner of the business and could not exercise any control over the target.

The US authorities have been seeking to revoke liability on successor companies, which directly participated in a violation or failed to stop the misconduct from continuing after the acquisition. In such cases, the purchasers' failure to conduct adequate due diligence and the ignoring of red flags that could have alerted them to the target's corrupt practices can be viewed as willful blindness on the part of the corporation. In 2009, for instance, Halliburton Company paid a penalty of $\$ 579$ million (combined criminal and civil penalty), on behalf of itself and its former subsidiary, KBR, in relation to a bribery scheme which began before Halliburton purchased KBR in 1998 and continued after the acquisition. Although Halliburton conducted a due diligence prior the acquisition, according to the SEC, Halliburton's due diligence was inadequate, as it failed to detect the bribery scheme and it ignored various red-flags relating to the use of overseas agents. ${ }^{2}$ Another recent example is the Mondelez International settlement with the SEC of 6 January 2017, according to which Mondelez paid $\$ 13$ million in relation to corrupt payments allegedly made through a local agent by an Cadbury India, a company which was acquired by Mondelez in 2010.

Accordingly, US authorities have been encouraging corporations to conduct pre-M\&A due diligence. By doing so, buyers are able to assess bribery and corruption risks of the target and subsequently reduce their legal exposure for pre-existing bribery and corruption practices, as well as the risk that such practices would continue after the conclusion of the transaction.

In the context of the FCPA, however, the M\&A transaction does not create retroactive liability when such liability was not in existence before the conclusion of the transaction. In the case of non-US companies, the FCPA applies to issuers and foreign companies that register securities on the US securities exchange. Otherwise, the application of FCPA requires other links to invoke US jurisdiction. Should the applicability conditions not apply to the target before conclusion of the M\&A transaction, no retroactive liability under FCPA should arise merely by the conclusion of the transaction. ${ }^{3}$ Nevertheless, when the bribery and corrupt practices continue after the conclusion of the $\mathrm{M} \& \mathrm{~A}$ transaction, the purchaser is exposed to liability risk for both pre- and post-M\&A violations.

\section{What is Anti-B Ribery Due Diligence All About?}

Anti-bribery due diligence is an assessment of the target company's bribery and corruption risk; that is, the likelihood that bribery and corrupt practices have been undertaken in the target business and their significance to the business. Accordingly, anti-bribery due diligence aims to identify facts and assess risks surrounding various aspects as detailed below:

- Enforcement records: are there previous, pending or expected investigations and enforcement actions relating to bribery and corrupt practices?

- Actual violations: are there bribery and corruption violations that have been taken place in recent years or are about to take place?

- Inherent risk: regardless of the existence and the effectiveness of controls or other mitigating factors, what is the likelihood of bribery or corrupt practices taking place? This

\footnotetext{
${ }^{2}$ For the SEC press release see: https://www.sec.gov/news/press/2009/2009-23.htm. For the DoJ press release see:http://www.justice.gov/opa/pr/kellogg-brown-root-llc-pleads-guilty-foreign-bribery-charges-andagrees-pay-402-million.

${ }^{3}$ This approach was stipulated by the US authority in: U.S. Department of Justice and S ecurities and Exchange Commission, Resource Guide to the U.S. Foreign Corrupt Practices Act (November 2012), available: http://www.justice.gov/sites/default/files/criminal-fraud/legacy/2015/01/16/guide.pdf. See also U.S. Department of Justice, Criminal Division, Opinion Procedure Release No.: 10-02: Foreign Corrupt Practices Act Review (7 November 2014), available at: http://www.justice.gov/sites/default/files/criminal fraud/legacy/2014/11/14/14-02.pdf.
} 
assessment is normally based on inherent bribery and corruption risk factors relating to the business, such as: industry, geographical operations, use of third parties, engagement with government officials, etc.

- Risk mitigation: does the target have an adequate compliance program in place, including sufficient support at the top, appropriate governance, policies, procedures, trainings, controls, internal reporting and whistle blowing systems, investigation and remedial procedures to adequately address bribery and corrupt practices?

- Control risk: how effective is the anti-bribery program of the target, and what is the likelihood of the program either failing to prevent or detect bribery and corruption?

- Residual risk: what is the likelihood of bribery and corrupt practices occurring after taking account of the mitigating effect of controls?

- Significance: what would be the likely impact on the target if a bribery or corrupt practice were discovered after completion of the acquisition? This evaluation may include, for instance, questions such as:

$>$ how robust is the target business without corrupt practices?

$>$ what are the costs of remediating the target's anti-bribery program?

$>$ what is the impact of enforcement (for example, regulatory or criminal enforcement or civil claims) on the target both from a financial and reputational perspective?

Given that under most anti-bribery and corruption laws, the target company may also be held accountable for bribery and corrupt practices undertaken by associated third parties, due diligence as outlined above should cover both the target company and its associated third parties. These would include, third parties providing services to the company or operating on its behalf, for example, subsidiaries, employees, agents, intermediaries, consultants, business partners, and joint-ventures.

\section{What Are The Benefits Of Conducting Anti-Corruption Due Diligence?}

Pre-transaction due diligence has several important benefits to companies as relate to: pre-existing violations, decisions that the M\&A team need to take, and controls that need to be exercised postacquisition:

- Backward looking - Liability mitigation: adequate due diligence would allow purchasers to identify past significant incidents and (potentially) problematic practices, and to adequately determine the response to them before moving on with the transaction. The identification of past issues does not necessarily entail that the transaction should be avoided altogether. Nevertheless, any further steps in relation to the transaction should be carefully considered against the risks involved in concluding the transaction. Additionally, undertaking an effective anti-bribery due diligence demonstrates the purchaser's genuine commitment to uncover bribery and corruption and may provide a basis for a lenient approach by law enforcers in the event or post-transaction detection of violation.

- Present benefit - adequate valuation: the risk of bribery and corruption as identified in pre-transaction due diligence allows the purchaser to better assess the value of the target corporation. Such risk may be noteworthy, for instance in cases in which a significant portion of the target's profit is produced through bribery or due to corrupt practices. Stopping those practices post-transaction may lead to a substantial devaluation of the target. Similarly, potential consequences of past incidents or pending investigations such as major fines, blacklisting consequences, reputational damage and spill-over effects, should all be taken into account when assessing the attractiveness of the transaction and the value of the target company.

- Forward looking - adequate controls: the assessment of the target bribery and corruption risk allows that purchaser to better prepare for post-transaction integration processes. Given the identified risks of the target, the purchaser is able to tailor a post-transaction integration plan so that it is well-designed to mitigate the target's bribery and corruption 
risks. The insights gained through the pre-transaction due diligence can, for instance, assist the purchaser in determining which further reviews and inquiries are required posttransaction to adequately address non-compliance risks. Similarly, based on those insights, the purchaser can effectively prioritize post-transaction anti-bribery program elements to be implemented post-closing.

\section{What is the ApPropriate LeVel of ANTI-Bribery Due Diligence?}

How broad should the scope of the assessment be? How much information is it necessary to gather and how deep is it necessary to dive into in the assessment of this information? The answer to these questions is provided on the basis of proportionality: The level of an adequate anti-bribery due diligence should be determined on a risk-basis, that is to say, the higher the bribery risk the more extensive the due diligence should be.

On a practical level, the level of due diligence should be determined by providing a preliminary answer to the various risks listed above. Initially, this assessment should take place at the early stages of the negotiation process based on the information available at the earliest point in time. Based on this preliminary assessment, a detailed due diligence place should be sketched, determining the scope and the due diligence steps to be taken. Obviously, at this early stage, the information available may be of poor quality, and thereby key risk dimensions may be overlooked, leading to the misjudgment of the adequacy of due diligence processes. Therefore, as a matter of good practice, the adequacy of the due diligence should be re-evaluated from time to time as the pre-transaction process progresses.

\section{How to Conduct an Anti-Corruption Due Diligence?}

Anti-bribery due diligence can take different forms of varying levels, duration, and costs. There is no uniform template procedure that perfectly fits all transactions. Nevertheless, in most cases, structuring the anti-bribery due diligence around the following steps may be useful to ensure its adequacy.

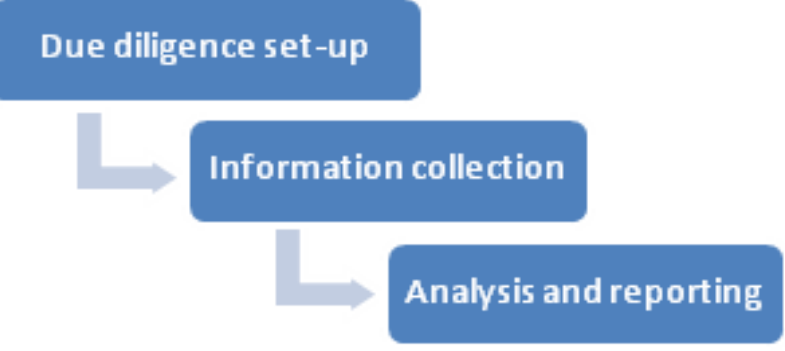

\section{Due diligence: process description}

Step1 - Due diligence set-up. Undertaking anti-bribery due diligence requires resources (for example, time, labor and budget) and may involve various challenges (for example, with respect to the availability of information and the target's limited willingness to cooperate). Hence, a crucial initial step in undertaking an M\&A due diligence is to secure management endorsement and support of the process. Once the required support is ensured, setting up the due diligence would commence with a preliminary risk assessment based on the information available at this phase, including corporate intelligence and background checks based on publicly available information and information shared by the target. Given the initial assessment, the level of due diligence will be determined and a detailed step-plan will be drawn to determine the scope of the exercise, the actual steps to be followed, roles and responsibilities, timeline including determining interim reporting, and final deliverables.

The due diligence assessment will always fall short of a complete review of all possible liability exposure of the target. Therefore, the due diligence team should be prepared to make risk-based choices relating to the scope when determining the periods to be assessed. One could take account of limitation periods applicable to the relevant target. Similarly, when the target is operating in various geographic markets or industries, prioritizing matters for review could take account of factors such as volume of business in each market, corruption perception score, previous incidents in the market and general enforcement trends.

Step2 - Information collection. In addition to the information collected from public sources and those voluntarily made available by the target, the due diligence would mostly rely on specific 
information provided by the target upon request of the purchaser. This request may refer to various documents, such as internal policies and procedures, organograms, internal reports, strategy documents, sales, distribution and supply chain information, procurement data, as well as audit and litigation documentation. Additionally, the purchaser may request the target to share and disclose specific information, clarify documents, and make statements and representations on various aspect through questionnaires or disclosure schedules. When appropriate, the purchaser may hold site-visits and interview sessions with the target's key personnel, such as marketing and sales directors, financial controllers, and the chief financial officer, to supplement the written information and documentation provided by the target. Another useful source of information in the target's financial administration system. Thus, a detailed review of the financial administrative system is recommended.

Step3 - analysis and reporting. Once the relevant data has been gathered, the due diligence turns to a deep-dive analytical phase, in which the risks of the target are evaluated and qualified (high, medium or low risk). Importantly, the analysis should cover all key bribery aspects relevant to the target. Those include both key risks of bribery and corrupt practices in which the target or its associated parties may be involved, as well as specific redflags and actual bribery practices as identified in the due diligence. With respect to the latter, the due diligence would evaluate the inherent bribery risk by looking at past records, and the scope, industry, geography and nature of the target of the business. It would then assess the existence and functioning of the internal compliance framework and the financial controls implemented by the target. Finally, the assessment would look at the residual risk after taking into account the mitigating effect of controls.

Based on this assessment, the due diligence would determine the likely impact on the target of a bribery practice that could be discovered after completion of the acquisition. When possible, the impact would be quantified in monetary terms to allow management to take that into account in the valuation of the target. In other cases, the impact would be qualified according to its level of significance and materiality.

\section{Due Diligence is COMPlete - What NeXT?}

Once the due diligence is complete, it is time for some decisions to be made. The purchaser is essentially required to decide whether to proceed with the transaction, and if so, under which conditions. This decision would normally depend on the significance and materiality of actual bribery practices and bribery risk identified in the due diligence, the ability of the purchaser to address the issues and mitigate those risks, and the risk appetite of the purchaser. For instance, when significant indications of bribery offenses are identified in a pre-transaction due diligence, some purchasers may perceive the transaction as exceeding their risk appetite and there by lead them to walk away unless the bribery issues are resolved before the conclusion of the transaction. This was the case with aerospace corporation, Lockheed Martin, which decided to terminate the merger agreement with Titan Corporation in June 2004.After announcing the planned acquisition, and as part of the review conducted with Titan, Lockheed Martin learned of allegations that improper payments had been made by Titan consultants to foreign officials. As a consequence, the merger agreement between the parties was amended to include a condition that Titan had to resolve the issues with the DOJ. Eventually, Titan's unresolved issues led Lockheed Martin to terminate the transaction in June 2004.

A different example is illustrated by the acquisition of InVision by General Electric. In that case, in the pre-acquisition due diligence of InVision, GE discovered payments made to local agents and distributors in China and other Asian countries. GE conditioned the execution of the transaction by requesting that InVision resolve the FCPA issues prior to concluding the acquisition. Accordingly, before the transaction closed, the parties voluntary disclosed the finding of the internal investigation to US authorities and entered into settlements with them. InVision paid a fine of USD 800,000 and agreed to continue it cooperation with the investigation. GE, in turn, agreed to enter a non-prosecution agreement with authorities, according to which, amongst other things, GE would integrate InVision into its compliance program and retain an independent consultant to evaluate the efficiency of the integration.

Purchasers may also decide to progress with the transaction but maintain the acquired company as an independent entity until the bribery issues are resolved. This was, for instance, the decision Johnson Controls Inc. made when acquiring York Corporation in 2005. Following the pre-acquisition discovery of corrupt practices and the disclosure to US authorities, the latter declined to prosecute 
Johnson Controls for York's pre-acquisition conduct. Instead, York's deferred prosecution agreement with the DOJ required Johnson to enhance York's internal controls.

\section{CONCLUSION}

Anti-bribery and corruption laws may hold a purchaser in an M\&A transaction liable for violations conducted by the acquired company, particularly when the purchaser was not prudent enough to assess those violations and address them adequately. Pre-acquisition bribery and corruption violations may transform into a lost value, post-transaction. Next to substantial fines imposed for corrupt practices, the purchaser may struggle with a long list of unexpected burdens, including: a costly public investigation, disturbance to business, lost business opportunities and pre-acquisition profit-generating business relationships, severe reputational damage and high costs of remediation.

Undertaking a proper, well-designed and professionally exercised compliance due diligence may keep purchasers away from trouble. Given the remarkable intensity of anti-bribery and corruption enforcement, anti-bribery due diligence has become an important means for corporations to reduce legal, reputational and transactional risks. The scope and the depth of the anti-bribery due diligence is to be determined on a case-by-case basis, given the risks involved and available resources, time and information. This article has canvassed key steps which could serve as a starting point for conducting anti-bribery due diligence.

Conducting a pre-acquisition anti-bribery due diligence is often not free of challenges. The success of its implementation depends on various factors, some of which cannot be controlled by the purchaser, such as the availability and access to relevant information. When the anti-bribery due diligence cannot be properly completed before a transaction, US authorities encourage corporations to complete their due diligence as soon as possible post-transaction to detect actual or potential corrupt practices and address them promptly. Further, after closing the deal, corporations are encouraged to promptly take the necessary steps to integrate the acquired business into the purchaser's anti-bribery framework. At this phase, compliance weakness and blackspots identified in the due diligence should be specifically addressed to ensure that the acquired company adheres to adequate standards of behaviour. $* * *$

Citation: Sharon Oded, Daniel Ceulen. “Anti-Bribery Due Diligence in M\&A Transactions: Have you Got it Covered?" International Journal of Managerial Studies and Research (IJMSR), vol 6, no. 7, 2018, pp. 14-19. doi:http://dx.doi.org/10.20431/2349-0349.0607002.

Copyright: (C) 2018 Authors. This is an open-access article distributed under the terms of the Creative Commons Attribution License, which permits unrestricted use, distribution, and reproduction in any medium, provided the original author and source are credited. 